\title{
The Demographics of Citizen Science Participation and Its Implications for Data Quality and Environmental Justice
}

\author{
Charlie Blake*, Allison Rhanor* and Cody Pajic ${ }^{\dagger}$
}

Citizen science programs have been growing in popularity in recent years and can provide various benefits to participants and their communities. We sought to determine whether these benefits are equitably accessible to all by examining potential demographic disparities in participation in our statewide citizen science program. We first explored whether Illinois RiverWatch participants are demographically and geographically representative of Illinois's population. We conducted online surveys of current participants to gather information on demographics, including race, income, and education level, and then compared these responses with the population of Illinois as a whole using (US) census data. We also examined whether RiverWatch stream sites are disproportionately located in areas of low environmental justice concern, as determined by the US Environmental Protection Agency's (US EPA's) Environmental Justice screening tool. We used GIS to map all stream sites $(n=936)$ and determined whether they were located in areas of high or low environmental justice concern. The survey data indicate that RiverWatch participants are disproportionately white, highly educated, and affluent compared with the Illinois general population. In addition, we found RiverWatch sites tend to be located in areas of lower environmental justice concern, and that areas of high environmental justice concern are underrepresented. We discuss how disparities in demographics of participants can not only indicate need for improvement in the accessibility of a citizen science program but could also harm the quality of the river-monitoring data collected, as it leads to sampling that is not accurately representative.

Keywords: citizen science; environmental justice; participant demographics; stream ecology

\section{Introduction}

Citizen science is a research model that often involves partnership between community members and accredited scientists to address a scientific question of mutual interest. Citizen science programs can be hyper-local or global in scope, can focus on collecting or analyzing data or both, and can stretch across many areas of study from astronomy to ornithology (Gugliucci et al. 2013; Hoffman et al. 2017; Mayor et al. 2017; Kimura and Kinchy 2016). Citizen science programs are not only helpful to scientists facing data-collection or data-processing challenges, but are also beneficial for participants as a learning opportunity, as a way to build social networks, and as a path to increase capacity for environmental advocacy (Domroese and Johnson 2017; Jordan et al. 2011). These programs also encourage increased communication and connection between academic institutions and communities (Dickinson et al. 2010; Yacoubian 2018; Roger and Klistorner 2016), and establishing this kind of

\footnotetext{
* University of Illinois Urbana-Champaign, Prairie Research Institute, Champaign, IL, US

+ Unity College, Unity, Maine, US

Corresponding author: Charlie Blake (charliekrblake@gmail.com)
}

two-way communication has the capacity to strengthen and enhance the abilities of both groups (Fischhoff and Scheufele 2019). Recognizing that participation in citizen science is a beneficial opportunity, it follows that ensuring equitable access to these opportunities should be an important part of building and managing citizen science programs. As research on citizen science has grown, there has been some attention paid to program participant demographics (Curtis 2018). This research has suggested that for many programs, participation is not reflective of the demographics of the population of potential participants but instead is concentrated among more privileged groups (Burgess et al. 2017; Pandya 2012).

Herein, we approach citizen science research with an environmental justice (EJ) lens, recognizing that some people are more severely and immediately impacted by environmental degradation than others as a result of multiple structural inequities that place them in harm's way with fewer resources to defend themselves and their environment (McGurty 1997; Cushing et al. 2015). The term environmental justice was coined in the 1980s to describe the disparities in the location of a variety of hazards such as superfund sites, oil pipelines, and wastewater treatment plants (UCC Commission for Racial Justice 1987; Wilson et al. 2008). These types of environmental hazards are 
frequently located near poor communities of color who have less social capital and less structural power to advocate for themselves and their environment, which we will refer to herein as EJ communities. Despite the attention environmental racism and EJ have received from some agencies, researchers, and activists since the terms were introduced several decades ago, inequitable distribution of environmental hazards remains widespread (Bullard et al. 2008). These unequal distributions of toxic pollution and degraded environments have been linked to health disparities that also continue to persist in communities of color (Morello-Frosch et al. 2001). While these communities suffer the most severe and immediate impacts, the persistence of environmental injustice negatively impacts everyone in the long run by allowing pollution to continue with fewer regulations (Cushing et al. 2015). A fundamental characteristic of networks of rivers, of course, is that everyone lives downstream from someone else, so merely moving sources of water pollution to certain communities does not prevent pollution and environmental degradation from eventually affecting everyone.

Citizen science can have many different goals depending on the organizational mission of those managing the program, but addressing EJ may often be one of them. Given the landscape of inequitable distribution of environmental degradation and the coupled disempowerment of those communities to defend their environment through more institutional channels, this positions citizen science as a powerful tool to allow these communities to gather knowledge that can aid in their ability to protect and/or access remediation resources for their environment (Ramirez-Andreotta et al. 2016; Wylie et al. 2016). For example, projects like the West Oakland Environmental Indicators Project and the Louisiana Bucket Brigade have harnessed the power of community data collectors to fight for better environmental protections in their communities (Scott 2016; Gonzalez et al. 2011). Citizen science is uniquely suited to place the power of scientific inquiry into the hands of communities that need it most: those embattled by environmental injustice who may also have less access to environmental monitoring through other institutional means (Heaney et al. 2011; Wylie et al. 2017). However, the potential for citizen science to play this role depends upon the accessibility of citizen science programs, their meaningful community collaborations, and their reach in at-risk EJ communities.

In the study presented here, we examine our own Illinois RiverWatch program as a case study for how issues of accessibility and EJ can play out in a large statewide citizen science program. Illinois RiverWatch has been operating for almost 25 years and has trained more than 3,000 citizen scientists to collect stream-monitoring data. One important characteristic of this program is that participants choose the stream sites they monitor, with many citizen scientists returning to the same site year after year. This means that the people in the program directly drive the research design by choosing the locations that will be monitored. We examined the demographics of our program participants to not only assess whether our program is accessible to people at high risk of experiencing environmental injustice, but also to investigate whether disparities in participation could be introducing bias into site selection and the scientific data we collect. Thus, we set out to determine if our RiverWatch participants are demographically and geographically representative of Illinois' population in general, and also whether RiverWatch stream site locations are underrepresenting areas of high EJ concern across the state. We assert that uncovering disparities in citizen science programs is important not only for the benefit of potential participants, but also for the quality of the data collected: Two stated goals of RiverWatch are to monitor rivers throughout the whole state and to obtain data that is accurately representative, generalizable, and complete.

\section{Methods}

Illinois RiverWatch is a volunteer stream-monitoring program that began in 1995 as a part of the Critical Trends Assessment Program operated by the Illinois Department of Natural Resources. The RiverWatch program transitioned to the National Great Rivers Research and Education Center (NGRREC) in 2006, a satellite campus of Lewis and Clark Community College. During the course of the program, Illinois RiverWatch citizen scientists have conducted stream monitoring on more than 900 stream sites around the state, with many volunteers returning to monitor the same stream annually. The training program consists of 6 hours of in-person instruction to become a certified citizen scientist, and includes hands-on experiential instruction in both an indoor space and an outdoor stream site. The RiverWatch program teaches citizen scientists to collect data on a variety of biological and physical characteristics of the river, with an emphasis on aquatic macroinvertebrates as bioindicators of overall stream health (Young 2015; Blake and Rhanor 2020). Following training, citizen scientists collect data on their own at stream sites around the state and later submit their written data on stream habitat conditions and types of macroinvertebrates collected, along with a physical sample of the preserved macroinvertebrates they collected. We also offer open laboratory sessions to assist citizen scientists in identifying what they have collected and to conduct outside quality control checks through the Illinois Natural History Survey.

We conducted an online survey to obtain demographic data on current RiverWatch participants. We built the survey in SurveyMonkey and sent the survey link to all of the citizen scientists who have participated in our program and for whom we had a recent viable email address through Constant Contact (824 email recipients). The survey made it clear to respondents that their responses would be confidential, as some questions contained sensitive information. We posed demographic questions that included inquiries about race, annual household income, and educational attainment; questions about their outof-pocket costs incurred from their participation in the program; and other questions on experiences in the citizen science program that may be used in future studies relating to civic engagement trust, and reciprocity. We obtained 100 responses, although not every respondent 
answered every question (race $n=94$, income $n=76$, education $n=95$, out-of-pocket costs $n=66$ ). We compared these responses to the general population of Illinois using data from the US Census Bureau from the 2017 data release of the American Community Survey (ACS), which is based on 5-year estimates summarizing 2012-2016, using Chi-square tests for race and education. We used the ACS 5-year estimate data because this is available for areas with smaller populations, rather than yearly data only from areas with populations above 65,000.

To examine how our sites are distributed compared with areas of greatest EJ concern, we used the US EPA's EJ screen tool. We specifically focused on the EJ index for wastewater discharge because our program has a focus on water quality in rivers. The wastewater discharge EJ index takes into account the 2019 modeled toxic concentrations at the stream segment level as well as the demographic factors that place populations at risk, including income, race, educational level, linguistic isolation, and age (EPA 2019). We have GPS coordinates for every sampling site in our database, and although these coordinates are based on the accuracy level of personal citizen scientists' devices (e.g., cell phones), we believe this level of accuracy is sufficient for the current study. We used the EJ screen tool to produce a map that assigned a percentile value representing the relative EJ concern for all areas across the state of Illinois, and then plotted our RiverWatch sites on top of this map. We then joined the EJ percentile rankings to the sites where our stream sampling took place to determine whether our sites are in areas of relatively high or low EJ concern. We used ArcMap 10.1 and RStudio 1.2.1335 to conduct these analyses.

\section{Results}

Our participant survey showed that the demographics of our citizen scientists are dissimilar to the population of Illinois as a whole. The observed distribution of race among participants in Illinois RiverWatch is significantly different than what would be expected based on the racial makeup of Illinois $\left(\chi^{2}=36.6, \mathrm{df}=6, \mathrm{p}<0.001\right)$. White participants make up $89 \%$ of the program compared with only $61 \%$ of the Illinois population (Figure 1). Similarly, the educational attainment of our participants is significantly different than what would be expected on the basis of the education levels among the general population $\left(\chi^{2}=158.6\right.$, df $\left.=4, \mathrm{p}<0.001\right)$. Illinois RiverWatch participants tend to be highly educated, with $40 \%$ having attained a graduate or professional degree, compared with only $11 \%$ of the population of Illinois (Figure 2). For the 76 respondents who reported their income, the median household income of our participants was $\$ 80,000$ to $\$ 84,999$, while the median income of Illinois, according to census data, was $\$ 62,992$.

We also explored in our survey questions some potential barriers to and hardships of participation. We discovered from our survey results that program participants spent an average of $\$ 26$ of their own money on gas, supplies, and postage to complete the stream-sampling process each year, in addition to paying the $\$ 50$ registration fee for our training course during their first year $(n=66)$. We also had some respondents mention in long-form responses the cost of their time itself. Some of our citizen scientists are in fact retired from fields in environmental science, and one person stated that if they had still been working, we would have had to pay at least $\$ 180$ for the time and expertise that they contribute to the project in a single monitoring season.

Next, we looked at how the geographic distribution of our sampling sites might affect the representational quality of our data. We explored the distribution of our sampling sites compared with areas of EJ concern as identified by the EPA EJ screen tool (Figure 3). We found that only 13 of our 933 sites are located in EJ hotspots with rankings above the $90^{\text {th }}$ percentile, and only 2 of these EJ

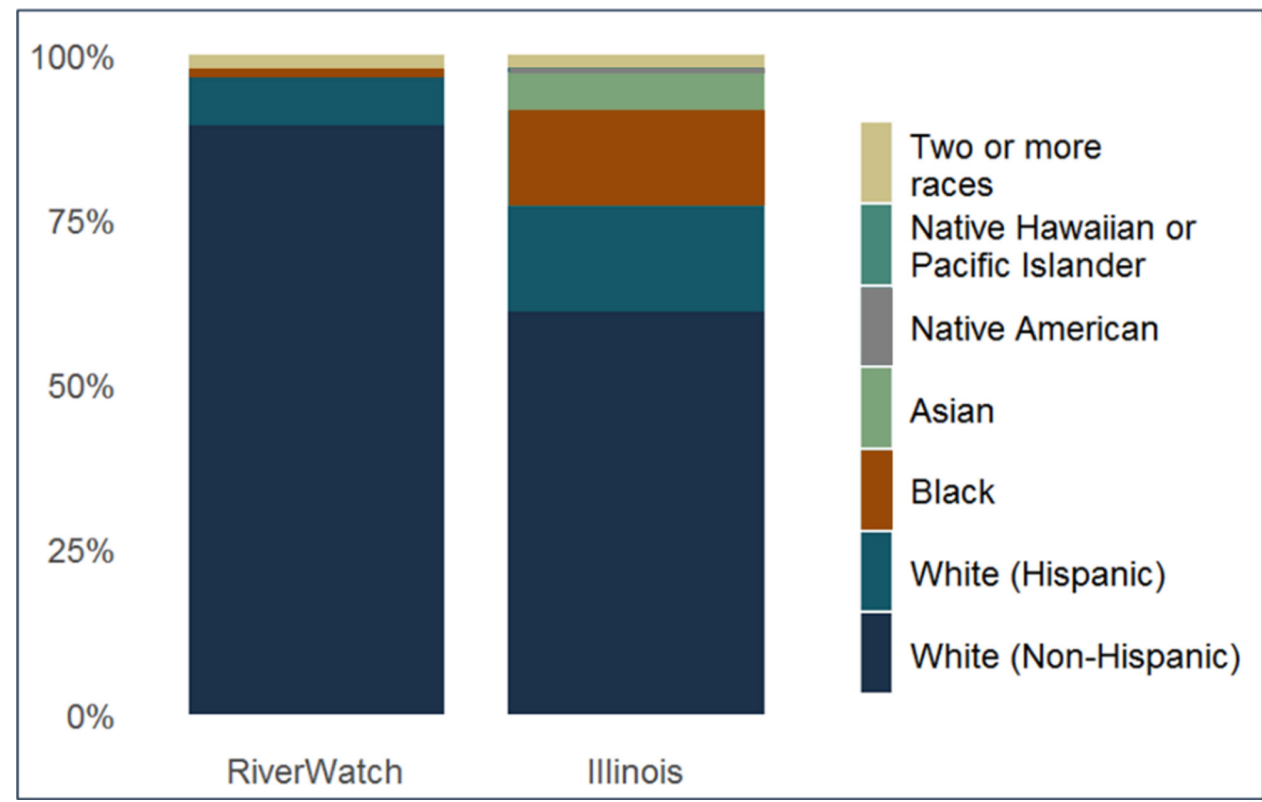

Figure 1: Racial demographics of RiverWatch citizen scientists from participant surveys $(\mathrm{N}=94)$ compared with the demographics of the Illinois population as a whole from the American Community Survey (2012-2016). 


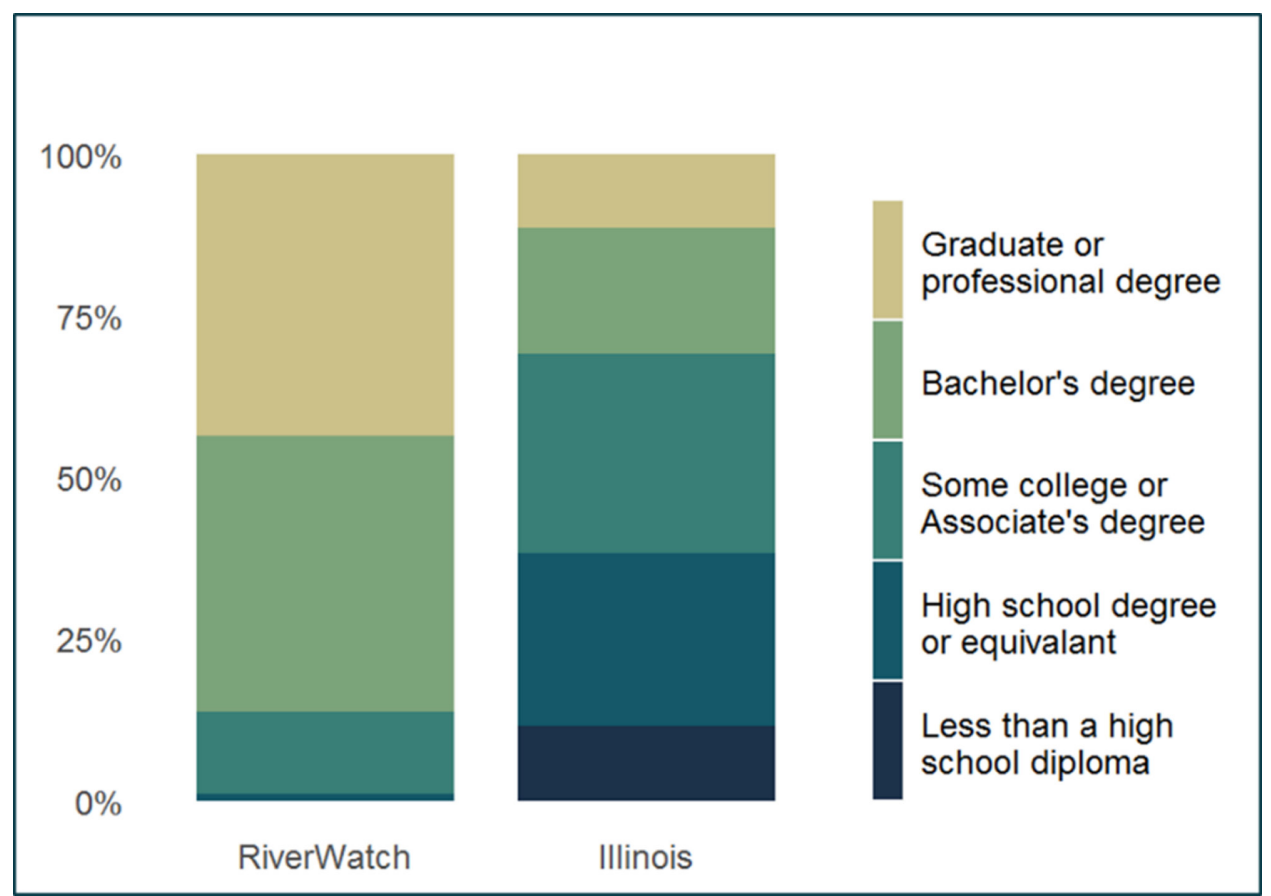

Figure 2: Education demographics of RiverWatch citizen scientists from participant surveys $(\mathrm{N}=95)$ compared with the demographics of the Illinois population as a whole from the American Community Survey (2012-2016).

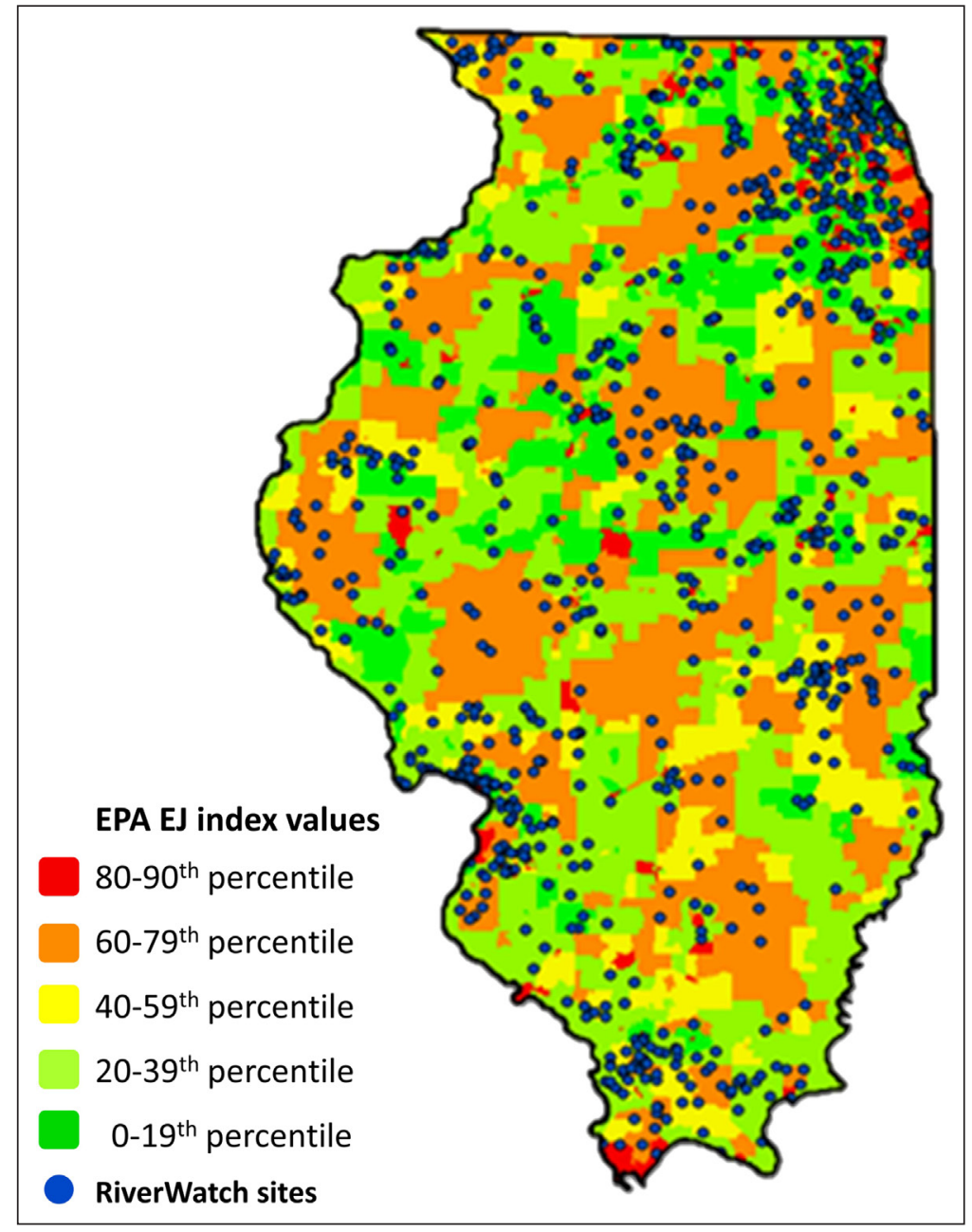

Figure 3: Location of RiverWatch monitoring sites overlaid on percentile rankings from United States Environmental Protection Agency (US EPA) wastewater discharge environmental justice (EJ) index values, which take into account both sociodemographic factors and environmental hazards. 


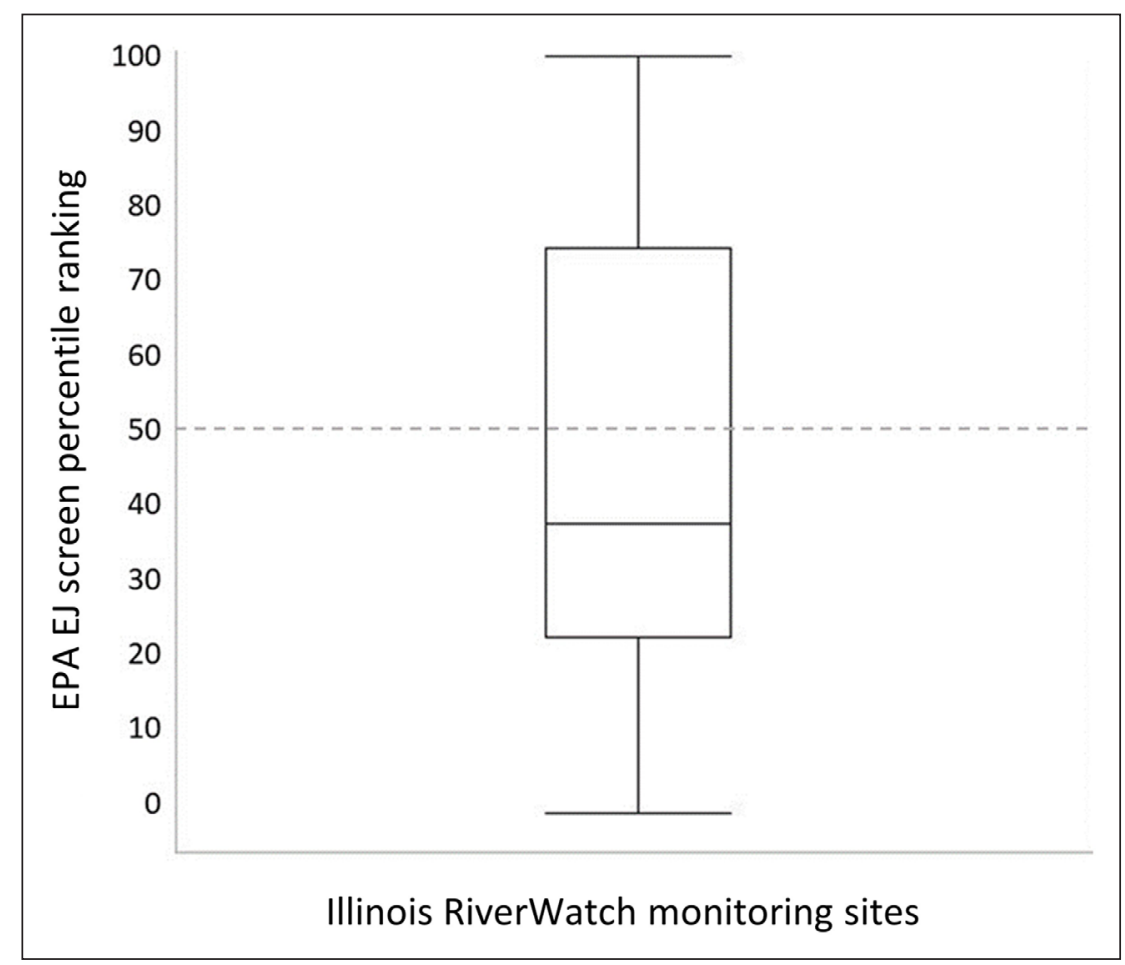

Figure 4: Percentile rankings from United States Environmental Protection Agency (US EPA) wastewater discharge environmental justice (EJ) index values of all RiverWatch sites, showing the distribution as compared to a reference line at the $50^{\text {th }}$ percentile. Only 13 of our sites are in located in EJ hotspot areas with rankings above the $90^{\text {th }}$ percentile $(\mathrm{N}=933$, Mean $\pm \mathrm{sd}=43.7 \pm 26$, Median $=38)$.

hotspot sites have been monitored by Illinois RiverWatch within the past five years (Figure 4). Our sampling sites skewed toward areas in the lower $50^{\text {th }}$ percentiles of EJ concern $(\mathrm{N}=933$, Mean $\pm \mathrm{sd}=43.7 \pm 26$, Median $=38$ ).

\section{Discussion}

One component of the mission of the NGRREC is to facilitate the communication of scientific findings to decision-makers in order to promote the creation of evidence-based natural resource management policy. The RiverWatch program has amassed a large dataset that provides valuable information on the health of Illinois's rivers over the past two decades. This data fills an important gap in our knowledge of stream conditions, a gap that existed because state and federal monitoring agencies do not have the staff and resources to monitor all of the state's waterways, and those that are monitored are often not monitored every year but rather on a rotational basis (Illinois Bureau of Water 2014). Our RiverWatch data is used by landowners, local and regional governments, natural resource managers, and academic scientists. For example, we are often contacted by agencies completing a watershed management plan, and we can supply them with data on a specific stream, county, or region that may have more specificity or more numerous sampling sites than data available from other sources. Thus, the reliability of our data to provide a representative picture of stream quality of all Illinois streams, not just those in parks and in good neighborhoods, is vital to the future of these environments. We also share our entire dataset with the online federal water quality exchange and sev- eral other online platforms, as well as producing a yearly report about our monitoring results that we send directly to participants and other fans of the program. Previous research has shown that environmental restoration funding can follow a pattern of reinforcing EJ disparities (Dernoga et al. 2015). Our worry is that citizen science programs like ours could inadvertently be contributing to a feedback loop in which some communities of people and their associated environments experience continued disinvestment and degradation. Whether the stream quality is in good or poor condition, the lack of data itself can be an issue, because natural resource managers are sometimes in the position of needing to show evidence of an environmental issue, or conversely, evidence of environments worth protecting, to direct resources and funding for effective protection and management to a particular area. Future research could explore not only the potential for RiverWatch activity to influence allocation of environmental protection and restoration funding, but also how this funding is distributed with respect to demographic factors of the surrounding communities.

Because of its long-standing collection protocols designed by the original professional scientists who served as project managers, the Illinois RiverWatch program might seem to be solely a "contributory project," meaning that participants primarily submit data and professional scientists design the project (Shirk et al. 2012). However, the power of site selection rests in the hands of the citizen scientists and gives them substantial influence over the design and ultimately the nature of the scientific knowledge produced. Choosing the locations of where stream 
monitoring occurs is actually a fundamental aspect of the study design. Although a high degree of participation from the public is sometimes lauded as a goal to strive for in citizen science programs, our case study illustrates how influence of participants in project design by itself does not always yield desirable outcomes. In this case, site selection by citizen scientists is a point in the project that can potentially introduce bias into the streammonitoring research. We have observed that the influence of participants in choosing sites actually leads to biased sampling of sites with lower EJ risk. One could compare this geographic disparity to several different benchmarks. If our sites were equally representing areas from all different levels of EJ concern, the mean and median EJ rank of our sites would be close to 50. If we were particularly serving EJ communities that might need citizen science environmental monitoring the most, we would expect a mean and median above the $50^{\text {th }}$ percentile. Given this bias, it is possible that we missed environmental issues needing attention in some areas, and that the stream data we've collected over the past $20+$ years of the program gave results showing a higher overall stream quality than was actually present across the state. Importantly, we want to emphasize that the disparities in participation in our program are what is driving this issue in sampling bias, not the fact that citizen scientists choose where they do their stream monitoring, which actually has many benefits. Citizen science programs can take advantage of the benefits of localized learning by emphasizing their placebased nature, building on the existing investment of participants in the environments where they live, and valuing learners' pre-existing knowledge as local experts (Boisselle 2016; Ramirez-Andreotta et al. 2015).

We recognize that it should not be merely an academic research exercise to quantify disparities in our program. Although it may seem odd to publicize the shortcomings of our own program, we believe this type of self-reflection and open discussion of the potential pitfalls of this work is necessary to work ethically in and advance the field of citizen science. There has also been an increasing emphasis on self-reflection and evaluation in the field of community-based research more broadly (Reese et al. 2019). However, our most immediate goal is actually not to increase diversity in our participation. It would be irresponsible to pursue diverse participation without first considering the power dynamics involved and the true costs and benefits of participation in our program in its current form. The current model of involvement in our program depends on a sacrifice economy as described by Liboiron (2019). This model requires our participants to pay for their own gear, pay to take our trainings, and volunteer their time to contribute data to our database. To simply ask less affluent Illinoisans to participate under these conditions is to demand greater sacrifices from the least privileged; it would be an increase in diversity, but a decrease in equity. Our first assumption must not be that everyone would participate in our program if they only knew about it, but rather that we are likely doing things in the way we run the program that makes participation out of reach for some potential participants. Our initial results suggest that the direct monetary cost of participation in our program is simply too high to merit broad participation. In addition to the direct cost of the $\$ 50$ registration fee we currently must charge to cover the costs of trainings, we are concerned about the indirect costs of participation. Further, we think the $\$ 26$ out-of-pocket cost reported by our survey respondents is likely an underestimate, because our relatively affluent participants may have taken for granted that they already own things like rubber boots and printer ink and did not include these costs in their survey responses. Indeed, the costs associated with the program may be considered negligible by our current volunteers because of their relatively high incomes. In fact, one volunteer mistakenly recorded on their survey that they had paid only $\$ 10$ for the required training, which perhaps suggests that they felt little difference between a cost of $\$ 50$ versus $\$ 10$. Additionally, the opportunity cost of attending a full Saturday training is also significant, especially for someone who may need to be using that time to care for family members or earn wages.

We also noted that the level of education attainment of our participants was markedly higher than the average Illinois resident. This suggests that as citizen science program coordinators, we give more thought to whether education and an increase in science literacy are really the most important or most effective aspects of our program. Many of our participants may not have a significant increase in science literacy beyond learning our particular program protocols if they already had extensive access to education through other avenues. This begs the question about what the most important motivations of our current participants are, and whether our program is actually designed to maximize the benefits our participants are seeking. Others have discussed the many different possible benefits or goals that a citizen science program may offer (Kimura and Kinchy 2016; Toomey and Domroese 2013), and although increasing science literacy, social capital, and capacity for environmental advocacy are all goals of our program, we have done little to measure whether we are achieving these goals or how we might change our program to better reflect these goals.

Our next steps will be to more thoroughly identify barriers and subsequent possible solutions to broadening participation in our program, as we feel it is important to focus on improving the power dynamics of participation before we start intentionally inviting a more socioeconomically diverse audience to participate. We have found many of the conversation starters available in toolkits developed by the Center for Advancement of Informal Science Education to be good starting places for further examinations of structural improvements that could be made to our program as we work toward broader participation (Bell et al. 2019). We have already begun to make programmatic changes to address some of the issues we have discovered, starting with changing training materials to actively combat stereotypes about who can be a part of scientific research (Long et al. 2001). We are also actively seeking funding to make more radical program changes with the goal of offering free trainings and potentially 
even financial incentives to citizen scientists who submit data, with the hope of increasing the accessibility of our program and creating a more balanced power dynamic with our participants (Liboiron 2019; Chesser et al. 2020). Ultimately, we suggest that if it is not possible to provide an equitable opportunity to participate owing to funding or staff constraints, it may be preferable to simply acknowledge the limited audience of our program for now, rather than expect less privileged Illinoisans to participate if we cannot offer them an empowering experience that will truly benefit them. It is possible to do community science in a way that promotes EJ, but does not demand a high degree of participation in the process from those who are already disempowered and negatively impacted by EJ, as exemplified by the work of the California Environmental Justice Collaborative (Kimura and Kinchy 2016; Morello-Frosch et al. 2012). We will also be exploring models that allow us to be responsive to the needs of embattled EJ communities without asking for large amounts of their unpaid labor, as well as how we can play a supporting role to EJ efforts in our region that are beyond the scope of the RiverWatch program itself.

We see this study as an example of how barriers to participation in the scientific process can actually lead to unreliable scientific data. This finding coincides with other research on the importance of diversity in decisionmaking and scientific advancement (Harding 1998; Page 2007). It is our goal to grow our ability to provide this vital information for more areas in Illinois, especially those we have reason to believe may be at greatest risk for environmental injustice and lack of monitoring data. By making our program more accessible to everyone, we hope that this will allow our program to better serve the whole state equitably, and areas of EJ concern in particular, as well as lead to better, more comprehensive data on Illinois streams. In future studies, we hope to explore further how the stream-quality data we collected from the sites our participants chose compares to more representative sampling of streams across the state, as well as to investigate the motivations participants have for choosing a particular stream site to study. Our findings are not unsurprising given previous research on participation in citizen science around other environmental topics has also noted socioeconomic disparities (Evans et al. 2005; Trumbull et al. 2000; Chase and Levine 2018). We hope that this study and the impetus it has provided us to make evidence-based improvements to our program will also be helpful to others working in citizen science, informal science education, and community-based research.

\section{Conclusion}

We set out to examine how the issues of race, income, educational background, and EJ may come into play in citizen science programs. Using the Illinois RiverWatch program as a case study, our findings support the notion that we cannot consider science learning or volunteer community science projects without also considering the sociopolitical and economic contexts in which these programs occur. Our participant survey showed that the demographics of our citizen scientists are markedly dis- similar from the population of Illinois as a whole with regard to race, income, and education attainment. Illinois RiverWatch participants are more white, more affluent, and more highly-educated compared with the general population of the state. We also discovered that stream sites monitored by our citizen scientists are drastically under-representing EJ hotspot areas within the state, with fewer than $2 \%$ of sites located in areas with an EJ percentile of $90^{\text {th }}$ or higher.

If as practitioners of citizen science our goals include the democratization of science, or unleashing the potential for citizen science to address EJ issues, we must consider disparities in citizen science participation and the likely barriers that may cause these disparities. Further, we have shown that if these issues are not addressed when a program is designed and subsequently administered, there is potential for repercussions that can result in lower quality data that is not a full representation of the study subject, in addition to repercussions of inequity for the people the program is attempting to serve. We posit that it is not just degree of participation that matters in examining the impact of citizen science on communities, but who is participating and what role they have in shaping the ultimate outcomes of the project. A citizen science program that is easily accessible only to privileged participants who already possess high degrees of financial and social capital could end up further exacerbating gaps in scientific literacy and capacity for environmental advocacy, unintentionally worsening EJ disparities between communities.

\section{Data Accessibility Statement}

The entire RiverWatch stream-quality database is available online in multiple locations including the EPA Water Quality Exchange and Fieldscope.org. The anonymized demographic data from our surveys will be available via Open Science Framework.

\section{Ethics and Consent}

Our research practices were in accordance with the Declaration of Helsinki. We obtained approval to conduct surveys with our participants through the institutional review board at Lewis and Clark Community College (IRB \#19-4). Our survey cover page clearly indicated that the participant survey was not mandatory and that the data collected would be kept anonymous. In addition, we follow Canadian Anti-Spam Legislation in our email practices. We also maintain yearly collection permits through the Illinois Department of Natural Resources that enforce our responsible handling of animals during our macroinvertebrate sampling (\#A19.6247). Finally, we strive to follow the guidance provided by the Jemez Principles for Democratic Organizing around environmental and economic justice (SNEEJ 1996) in our research and management of this program.

\section{Acknowledgements}

We thank Monica Ramirez-Andreotta, her lab, and the Gardenroots project for inspiration and guidance in developing this project. We thank the National Great River 
Research and Education Center for internship funding that supported Cody Pajic in participating in this research. We appreciate Sharon Locke for her thoughts on this work and her co-authorship on related funding proposals. We thank two anonymous reviewers for their helpful suggestions that improved the manuscript. We also appreciate the many government and non-profit partners who lent us space for trainings and helped us recruit volunteers for this state-wide program. And of course, we are deeply indebted to all of our current and past citizen scientists for their invaluable contributions to this program.

\section{Competing Interests}

The authors have no competing interests to declare.

\section{Author Contributions}

Charlie Blake and Allison Rhanor conceived of and designed the study. Cody Pajic conducted the participant surveys and map analyses and created some of the figures. Charlie Blake conducted all statistical analyses, wrote the first draft of the manuscript, and in addition directed the operation of the Illinois RiverWatch program. Allison Rhanor wrote and edited subsequent drafts of the manuscript.

\section{References}

Bell, J, Bevan, B, Barton, AC, Garibay, C, Ballard, M, Burks, R, Lesser, M, Choi, M, Maryboy, N, McCreedy, D, Menezes, S, Pinkard, N, Reich, C, Takahashi, B, Upadhyay, B and Watt, D. 2019. Broadening perspectives on broadening participation in STEM: A toolkit to support science engagement professionals who are developing strategic efforts to broaden participation in STEM. National Science Foundation: Advancing Informal Science Learning, 1 May 2019. https://www. informalscience.org/broadening-perspectives-broadening-participation-stem-toolkit-support-scienceengagement.

Blake, C and Rhanor, A. 2020. The impact of channelization on macroinvertebrate bioindicators in small order Illinois streams: Insights from long-term citizen science research. Aquatic Sciences, 82(35). DOI: https://doi.org/10.1007/s00027-020-0706-4

Boisselle, LN. 2016. Decolonizing science and science education in a postcolonial space (Trinidad, a developing Caribbean nation, illustrates). SAGE Open, 6(1). DOI: https://doi.org/10.1177/2158244016635257

Bullard, RD, Mohai, P, Saha, R and Wright, B. 2008. Toxic wastes and race at twenty: Why race still matters after all these years. Environmental Law, 38(2): 371411.

Burgess, HK, DeBey, LB, Froehlich, HE, Schmidt, N, Theobald, EJ, Ettinger, AK, HilleRisLambers, J, Tewksbury, J and Parrish, JK. 2017. The science of citizen science: Exploring barriers to use as a primary research tool. Biological Conservation, 208: 113-120. DOI: https://doi.org/10.1016/j.biocon.2016.05.014

Chase, SK and Levine, A. 2018. Citizen Science: Exploring the Potential of Natural Resource Monitoring
Programs to Influence Environmental Attitudes and Behaviors. Conservation Letters, 11(2). DOI: https:// doi.org/10.1111/conl.12382

Chesser, S, Porter, MM and Tuckett, AG. 2020. Cultivating citizen science for all: Ethical considerations for research projects involving diverse and marginalized populations. International Journal of Social Research Methodology, 23(5): 497-508. DOI: https://doi.org/1 $0.1080 / 13645579.2019 .1704355$

Curtis, V. 2018. Who Takes Part in Online Citizen Science? Online Citizen Science and the Widening of Academia: Distributed Engagement with Research and Knowledge Production, 45-68. DOI: https://doi.org/10.1007/9783-319-77664-4_3

Cushing, L, Morello-Frosch, R, Wander, $\mathbf{M}$ and Pastor, M. 2015. The Haves, the Have-Nots, and the Health of Everyone: The Relationship Between Social Inequality and Environmental Quality. Annual Review of Public Health, 36: 193-209. DOI: https://doi.org/10.1146/ annurev-publhealth-031914-122646

Dernoga, MA, Wilson, S, Jiang, CS and Tutman, F. 2015. Environmental justice disparities in Maryland's watershed restoration programs. Environmental Science \& Policy, 45: 67-78. DOI: https://doi.org/ 10.1016/j.envsci.2014.08.007

Dickinson, JL, Zuckerberg, B and Bonter, DN. 2010. Citizen Science as an Ecological Research Tool: Challenges and Benefits. Annual Review of Ecology, Evolution, and Systematics, 41: 149-172. DOI: https:// doi.org/10.1146/annurev-ecolsys-102209-144636

Domroese, MC and Johnson, EA. 2017. Why watch bees? Motivations of citizen science volunteers in the Great Pollinator Project. Biological Conservation, 208: 40-47. DOI: https://doi.org/10.1016/j.biocon. 2016.08.020

EPA, United States Environemntal Protection Agency. 2019. EJSCREEN. https://www.epa.gov/ejscreen.

Evans, C, Abrams, E, Reitsma, R, Roux, K, Salmonsen, L and Marra, PP. 2005. The Neighborhood Nestwatch program: Participant outcomes of a citizen-science ecological research project. Conservation Biology, 19(3): 589-594. DOI: https://doi.org/10.1111/j.15231739.2005.00s01.x

Fischhoff, B and Scheufele, DA. 2019. The Science of Science Communication III. Proceedings of the National Academy of Sciences of the United States of America, 116(16): 7632-7633. DOI: https://doi. org/10.1073/pnas.1902256116

Gonzalez, PA, Minkler, M, Garcia, AP, Gordon, M, Garzon, C, Palaniappan, M, Prakash, S and Beveridge, B. 2011. Community-Based Participatory Research and Policy Advocacy to Reduce Diesel Exposure in West Oakland, California. American Journal of Public Health, 101: S166-S175. DOI: https://doi. org/10.2105/AJPH.2010.196204

Gugliucci, N, Gay, P and Bracey, G. 2013. Citizen Science Motivations as Discovered with CosmoQuest. Pages 437-440. Book Citizen Science Motivations as Discovered with CosmoQuest. City. 
Harding, S. 1998. Women, science, and society. Science, 281(5383): 1599-1600. DOI: https://doi.org/10.1126/ science.281.5383.1599

Heaney, C, Wilson, S, Wilson, O, Cooper, J, Bumpass, J and Snipes, M. 2011. Use of community-owned and -managed research to assess the vulnerability of water and sewer services in marginalized and underserved environmental justice communities. Journal of Environmental Health, 74(1): 8-17. DOI: https://doi. org/10.1289/isee.2011.00095

Hoffman, C, Kennedy, EB, Cooper, CB, Farooque, M and Cavalier, D. 2017. SciStarter 2.0: A Digital Platform to Foster and Study Sustained Engagement in Citizen Science. Analyzing the Role of Citizen Science in Modern Research, 50-61. DOI: https://doi.org/10.4018/978-15225-0962-2.ch003

Illinois Bureau of Water. 2014. Illinois Water Monitoring Strategy 2015-2020. Springfield, IL.

Jordan, RC, Gray, SA, Howe, DV, Brooks, WR and Ehrenfeld, JG. 2011. Knowledge Gain and Behavioral Change in Citizen-Science Programs. Conservation Biology, 25(6): 1148-1154. DOI: https://doi.org/10. 1111/j.1523-1739.2011.01745.x

Kimura, AH and Kinchy, A. 2016. Citizen Science: Probing the Virtues and Contexts of Participatory Research. Engaging Science Technology and Society, 2: 331-361. DOI: https://doi.org/10.17351/ests2016.99

Liboiron, M. 2019. The power (relations) of citizen science. In: Citizen Science Association Annual Meeting. Raleigh, NC on 14 March, 2019.

Long, M, Boiarsky, G and Thayer, G. 2001. Gender and racial counter-stereotypes in science education television: A content analysis. Public Understanding of Science, 10(3): 259-273.

Mayor, SJ, Guralnick, RP, Tingley, MW, Otegui, J, Withey, JC, Elmendorf, SC, Andrew, ME, Leyk, S, Pearse, IS and Schneider, DC. 2017. Increasing phenological asynchrony between spring green-up and arrival of migratory birds. Scientific Reports, 7: 10. DOI: https://doi.org/10.1038/s41598-017-02045-z

McGurty, EM. 1997. From NIMBY to civil rights - The origins of the environmental justice movement. Environmental History, 2(3): 301-323. DOI: https://doi. org/10.2307/3985352

Morello-Frosch, R, Pastor, M and Sadd, J. 2001. Environmental justice and Southern California's "riskscape" - The distribution of air toxics exposures and health risks among diverse communities. Urban Affairs Review, 36(4): 551-578. DOI: https://doi.org/10. $1177 / 10780870122184993$

Morello-Frosch, R, Pastor, M and Sadd, J. 2012. Environmental Justice and the Precautionary Principle Air Toxics Exposures and Health Risks among Schoolchildren in Los Angeles. Contested Illnesses: Citizens, Science, and Health Social Movements, 64-76. DOI: https://doi.org/10.1525/california/9780520270 206.003.0005

Page, SE. 2007. Making the difference: Applying a logic of diversity. Academy of Management Perspectives,
21(4): 6-20. DOI: https://doi.org/10.5465/amp.2007. 27895335

Pandya, RE. 2012. A framework for engaging diverse communities in citizen science in the US. Frontiers in Ecology and the Environment, 10(6): 314-317. DOI: https://doi.org/10.1890/120007

Ramirez-Andreotta, MD, Brody, JG, Lothrop, N, Loh, M, Beamer, PI and Brown, P. 2016. Improving environmental health literacy and justice through environmental exposure results communication. International Journal of Environmental Research and Public Health, 13(7): 27. DOI: https://doi.org/10.3390/ ijerph 13070690

Ramirez-Andreotta, MD, Brusseau, ML, Artiola, J, Maier, RM and Gandolfi, AJ. 2015. Building a cocreated citizen science program with gardeners neighboring a superfund site: The Gardenroots case study. International Public Health Journal, 7(1).

Reese, AL, Hanza, MM, Abbenyi, A, Formea, C, Meiers, SJ, Nigon, JA, Osman, A, Goodson, M, Njeru, JW, Boursaw, B, Dickson, E, Wieland, ML, Sia, IG and Wallerstein, N. 2019. The Development of a Collaborative Self-Evaluation Process for CommunityBased Participatory Research Partnerships Using the Community-Based Participatory Research Conceptual Model and Other Adaptable Tools. Progress in Community Health Partnerships: Research, Education, and Action, 13(3): 223-224. DOI: https://doi.org/10.1353/ cpr.2019.0049

Roger, E and Klistorner, S. 2016. BioBlitzes help science communicators engage local communities in environmental research. Journal of Science Communication, 15(3). DOI: https://doi.org/10.22323/2.15030206

Scott, DN. 2016. 'We Are the Monitors Now': Experiential Knowledge, Transcorporeality and Environmental Justice. Social \& Legal Studies, 25(3): 261-287. DOI: https://doi.org/10.1177/0964663915601166

Shirk, JL, Ballard, HL, Wilderman, CC, Phillips, T, Wiggins, A, Jordan, R, McCallie, E, Minarchek, M, Lewenstein, BV, Krasny, ME and Bonney, R. 2012. Public Participation in Scientific Research: A Framework for Deliberate Design. Ecology and Society, 17(2): 20. DOI: https://doi.org/10.5751/ES-04705-170229

SNEEJ, Southwest Network for Environmental and Economic Justice. 1996. Jemez Principles for Democratic Organizing. Working Group Meeting on Globalization and Trade, 6-8 December 1996. Jemez Springs, NM.

Toomey, AH and Domroese, MC. 2013. Can citizen science lead to positive conservation attitudes and behaviors? Human Ecology Review, 20(1): 50-62.

Trumbull, DJ, Bonney, R, Bascom, D and Cabral, A. 2000. Thinking scientifically during participation in a citizen-science project. Science Education, 84(2): 265-275. DOI: https://doi.org/10.1002/(SICI)1098237X(200003)84:2<265::AID-SCE7>3.0.CO;2-5

United Church of Christ Comission for Racial Justice. 1987. Toxic Wastes and Race in the United States. New York: Commission for Racial Justice. 
Wilson, SM, Hutson, MA and Mujahid, MS. 2008. How Planning and Zoning Contribute to Inequitable Development, Neighborhood Health, and Environmental Injustice. Environmental Justice, 1(4): 211-216. DOI: https://doi.org/10.1089/env.2008.0506

Wylie, S, Schultz, K, Thomas, D, Kassotis, C and Nagel, S. 2016. Inspiring collaboration: the legacy of Theo Colborn's transdisciplinary research on fracking. New Solutions-a Journal of Environmental and Occupational Health Policy, 26(3): 360-388. DOI: https://doi. org/10.1177/1048291116666037
Wylie, S, Shapiro, N and Liboiron, M. 2017. Making and doing politics through grassroots scientific research on the energy and petrochemical industries. Engaging Science, Technology, and Society, 3: 393-425. DOI: https://doi.org/10.17351/ests2017.134

Yacoubian, HA. 2018. Scientific literacy for democratic decision-making. International Journal of Science Education, 40(3): 308-327. DOI: https://doi.org/10.1 080/09500693.2017.1420266

Young, M, editor. 2015. Illinois RiverWatch Stream Monitoring Manual, 9th edition. East Alton, IL.

How to cite this article: Blake, C, Rhanor, A and Pajic, C. 2020. The Demographics of Citizen Science Participation and Its Implications for Data Quality and Environmental Justice. Citizen Science: Theory and Practice, 5(1): 21, pp. 1-10. DOl: https://doi. org/10.5334/cstp.320

Copyright: () 2020 The Author(s). This is an open-access article distributed under the terms of the Creative Commons Attribution 4.0 International License (CC-BY 4.0), which permits unrestricted use, distribution, and reproduction in any medium, provided the original author and source are credited. See https://creativecommons.org/licenses/by/4.0/. 